Supplemental Information for: Source-to-tap Assessment of Microbiological Water Quality in Small Rural Drinking Water Systems in Puerto Rico Six Months after Hurricane Maria

Authors: Ishi Keenum ${ }^{1}$, Melitza Crespo Medina ${ }^{2}$,Emily Garner ${ }^{3}$, Kelsey J. Pieper ${ }^{4}$, Matthew Forrest Blair $^{1}$, Erin Milligan ${ }^{1}$, Amy Pruden $^{1 *}$, Graciela Ramirez-Toro ${ }^{2}$, William J. Rhoads ${ }^{* 1}$

${ }^{1}$ Virginia Tech, Department of Civil \& Environmental Engineering, Blacksburg, VA 24060

${ }^{2}$ Inter American University, Center for Environmental Education, Conservation and Research, San Germán, PR 00683

${ }^{3}$ West Virginia University, Department of Civil \& Environmental Engineering, Morgantown, WV 26506

${ }^{4}$ Northeastern University, Department of Civil \& Environmental Engineering, Boston, MA 02115

*Co-corresponding authors: William Rhoads wrhoads@ vt.edu;Amy Pruden apruden@ vt.edu 


\section{Physiochemical Data}

System SC2 experienced high total lead in the distribution system samples, ranging from $<1$ to $61.2 \mathrm{ppb}$ (average 31.6 $\pm 34.7 \mathrm{ppb}$ ). The maximum lead sample also had the highest iron (490 ppb) and copper $(8.7 \mathrm{ppb})$ concentrations, highlighting corrosion concerns. In systems that had functioning chlorination at the time of sampling, free chlorine generally decreased in the distribution system (by $0-1.92 \mathrm{mg} / \mathrm{L}$ relative to "distribution system" samples) and in first flush

distribution system samples (by $0-2.9 \mathrm{mg} / \mathrm{L}$ relative to "distribution system" samples). Other trends were not noteworthy (Table $\mathrm{S} 4$ ).

\section{SI Figures and Tables:}




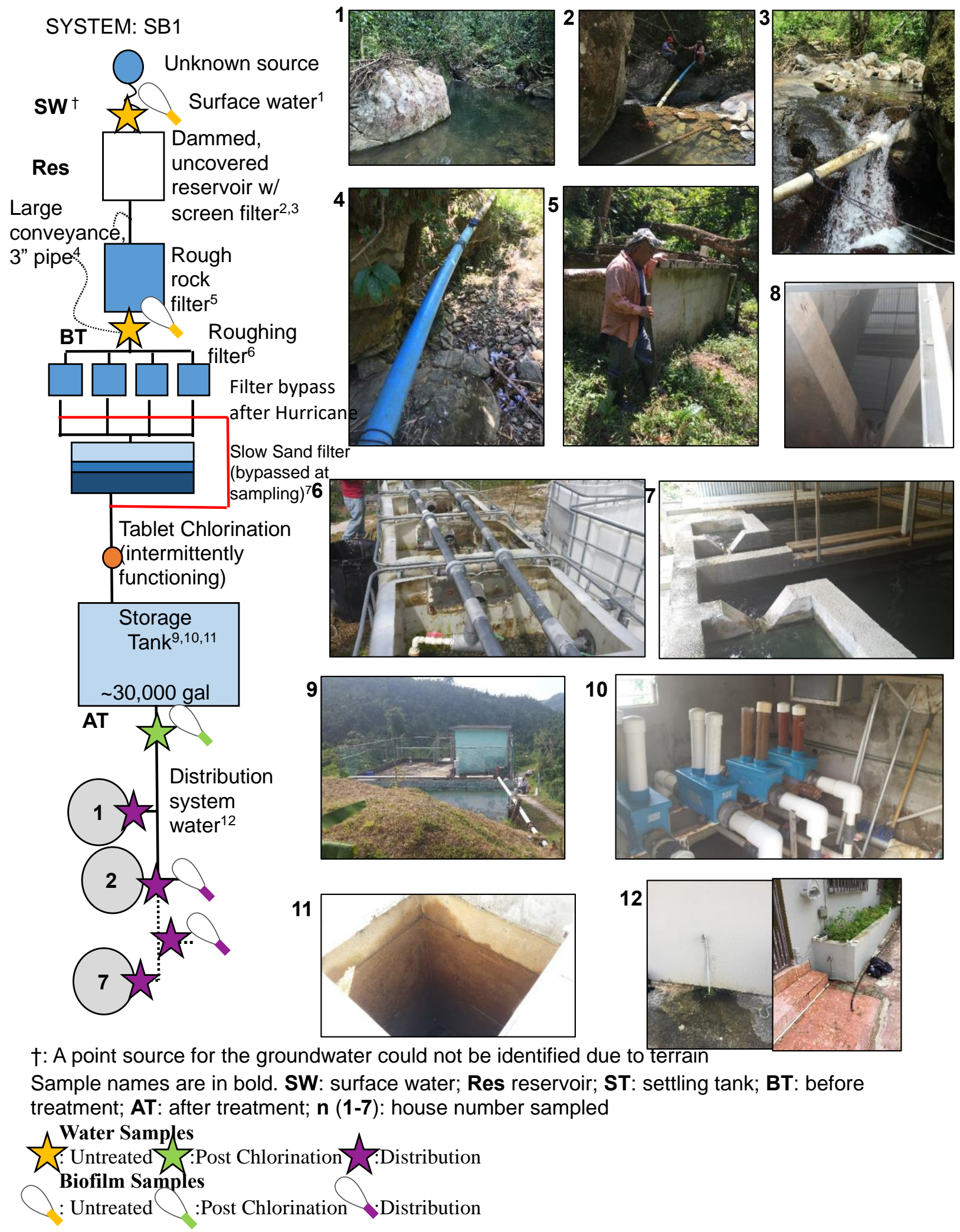

Figure S1: System SB1: process diagrams, sampling locations, and descriptions 


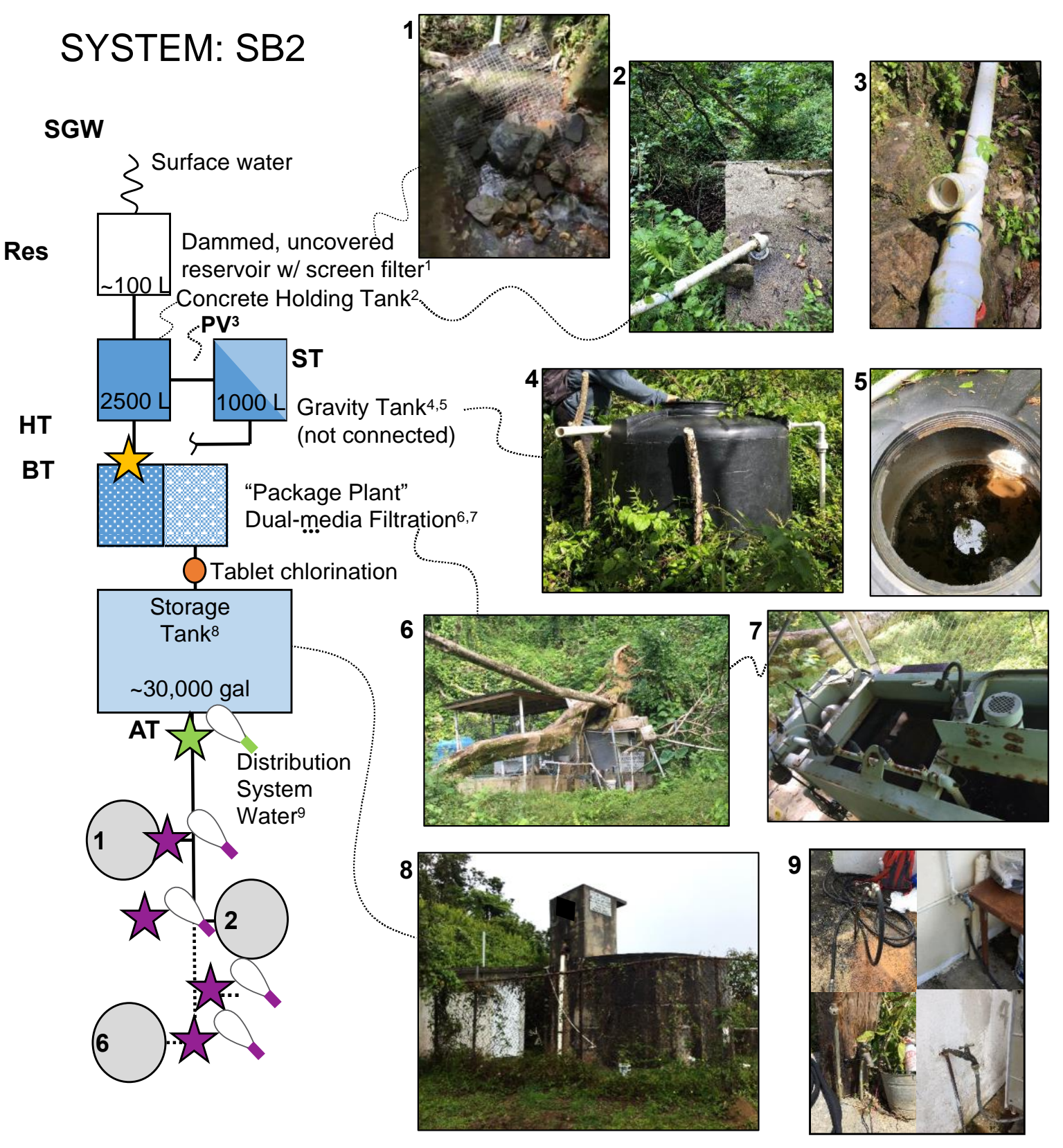

Sample names are in bold. SGW: surface impacted ground water; Res: reservoir; HT: holding tank; ST: settling tank; PV: pipe vent to facilitate flow; BT: before treatment; AT: after treatment; $\mathbf{n}(\mathbf{1 - 6})$ : house number sampled

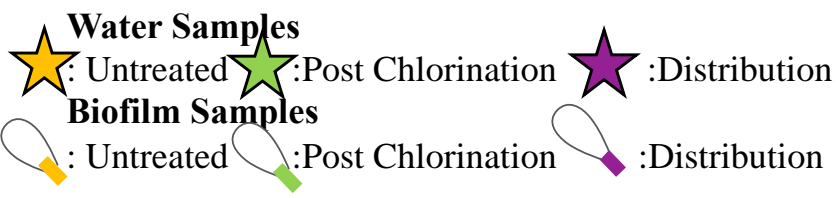

Figure S2: System SB2: process diagrams, sampling locations, and descriptions 

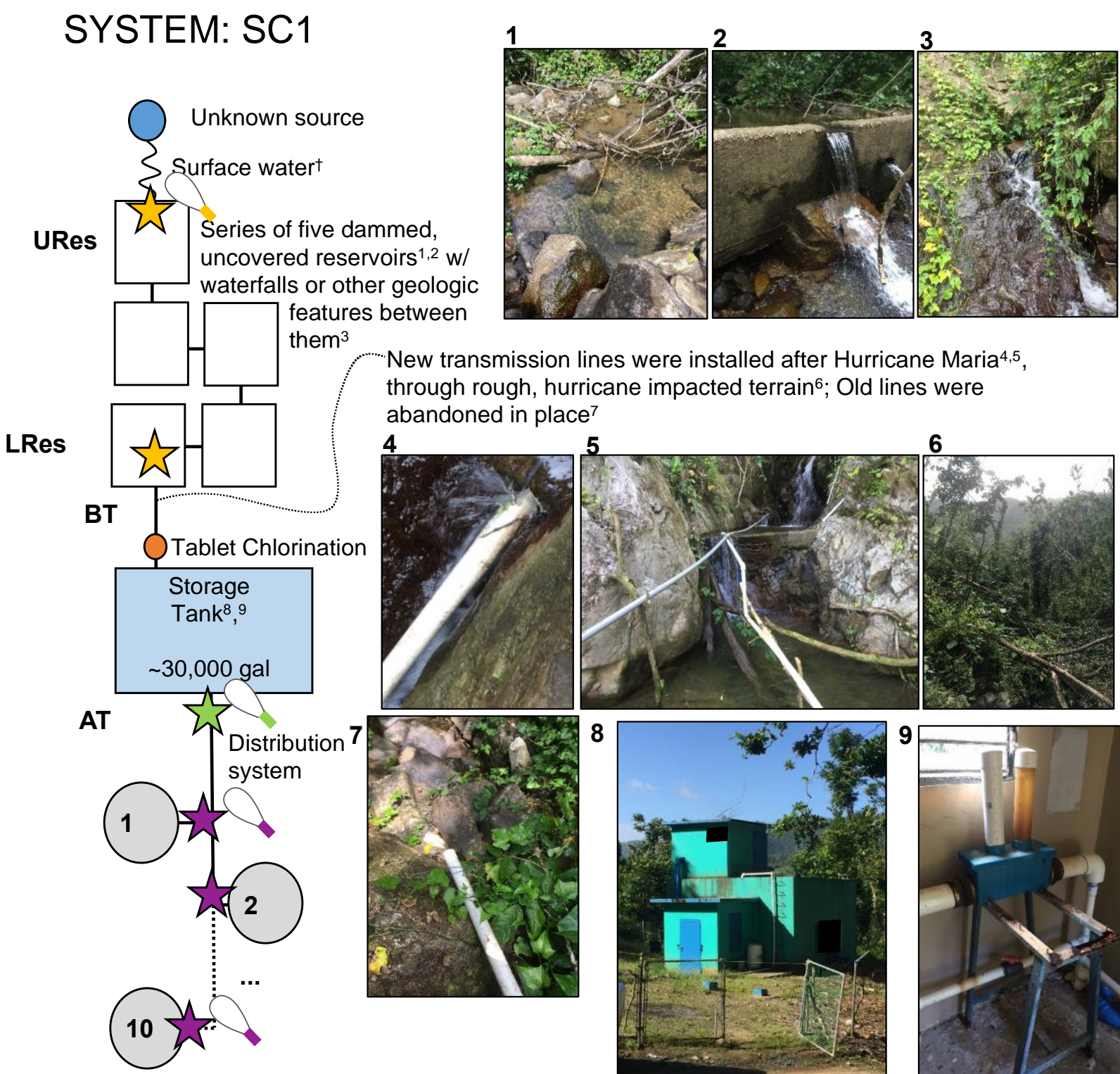

New transmission lines were installed after Hurricane Maria ${ }^{4,5}$, impacted terrain 6 ; Old lines were

LRes
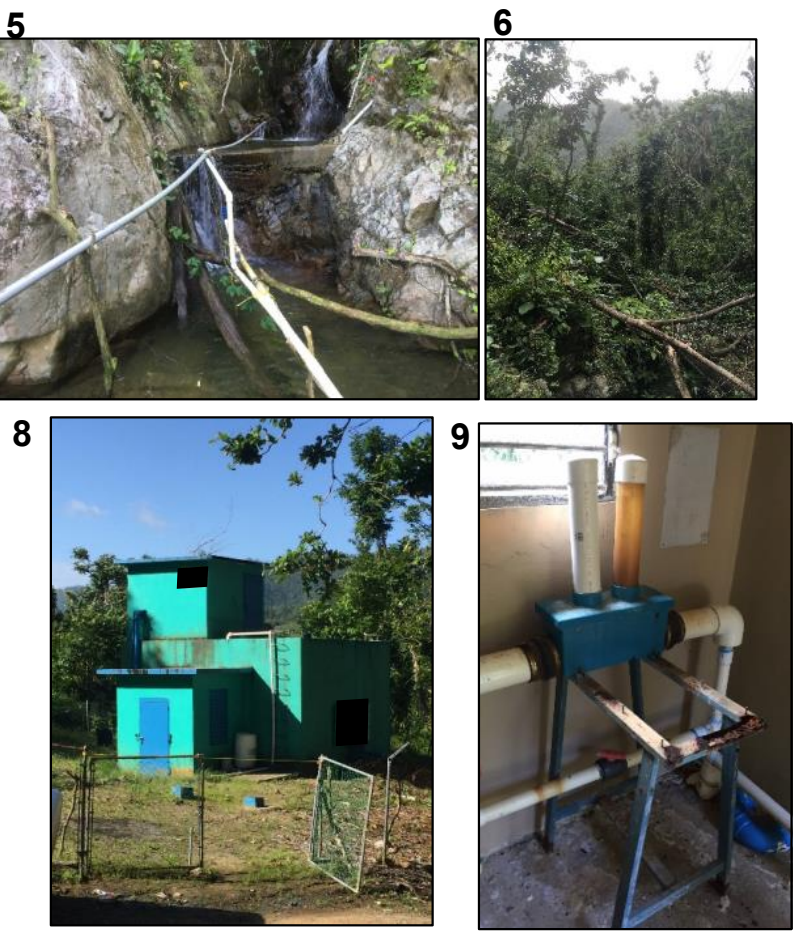

$\dagger$ : A point source for the groundwater could not be identified due to terrain

Sample names are in bold. SGW: surface impacted ground water; URes: upper-most reservoir; LRes: lowermost reservoir; HT: holding tank; ST: settling tank; BT: before treatment; AT: after treatment; $\mathbf{n}$ (1-10): house number sampled

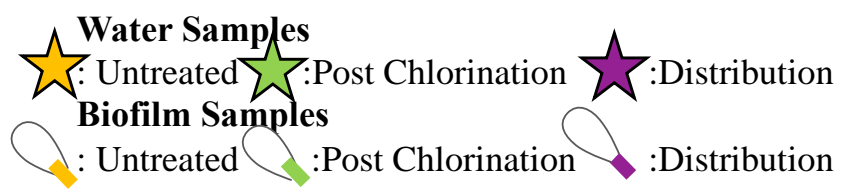


Figure S3: System SC1: process diagrams, sampling locations, and descriptions

\section{SYSTEM: SC2}

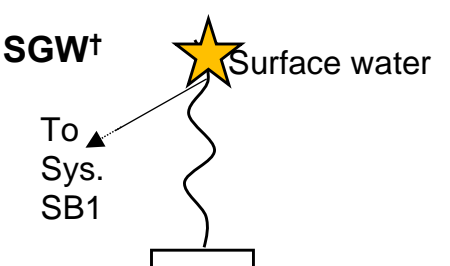

Res

Dammed, uncovered
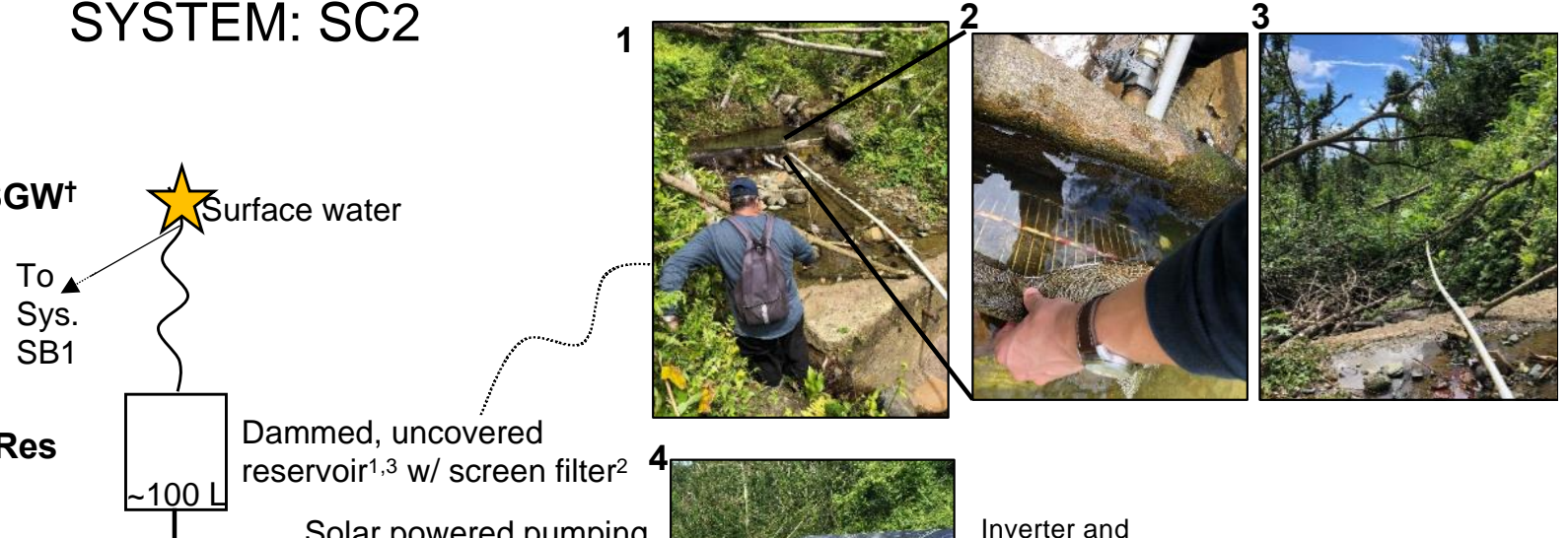

reservoir ${ }^{1,3} \mathrm{w} /$ screen filter $^{2}$
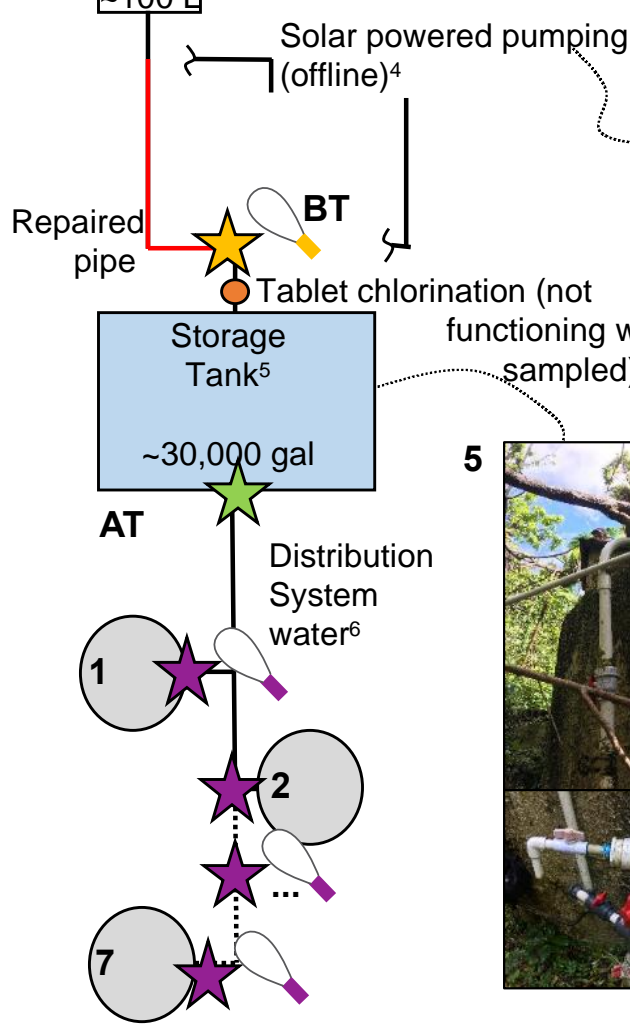

functioning when

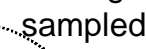

5
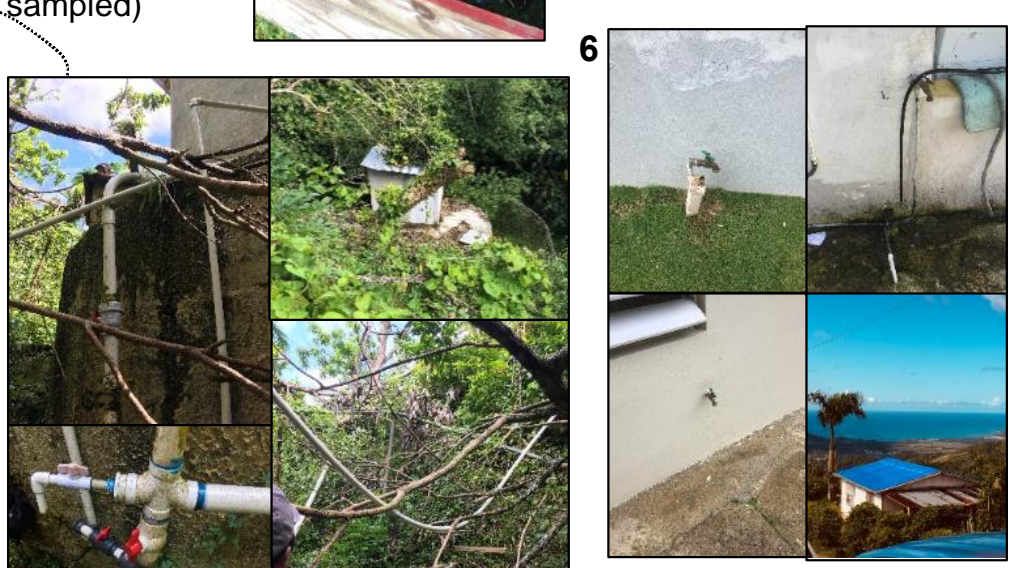

†: Groundwater source for System SFC2 and SC are the same, System SC dams the surface water downstream of System SFC2

Sample names are in bold. SGW: surface impacted ground water; Res: reservoir; BT: before treatment; AT: after treatment; $\mathbf{n}$ (1-7): house number sampled

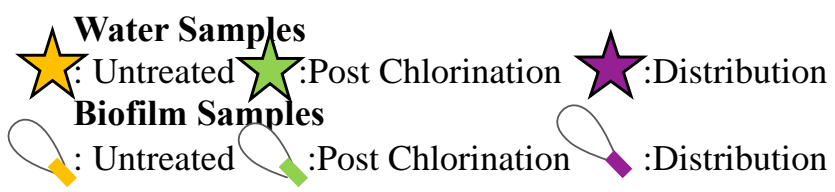

Figure S4: System SC2: process diagrams, sampling locations, and descriptions 

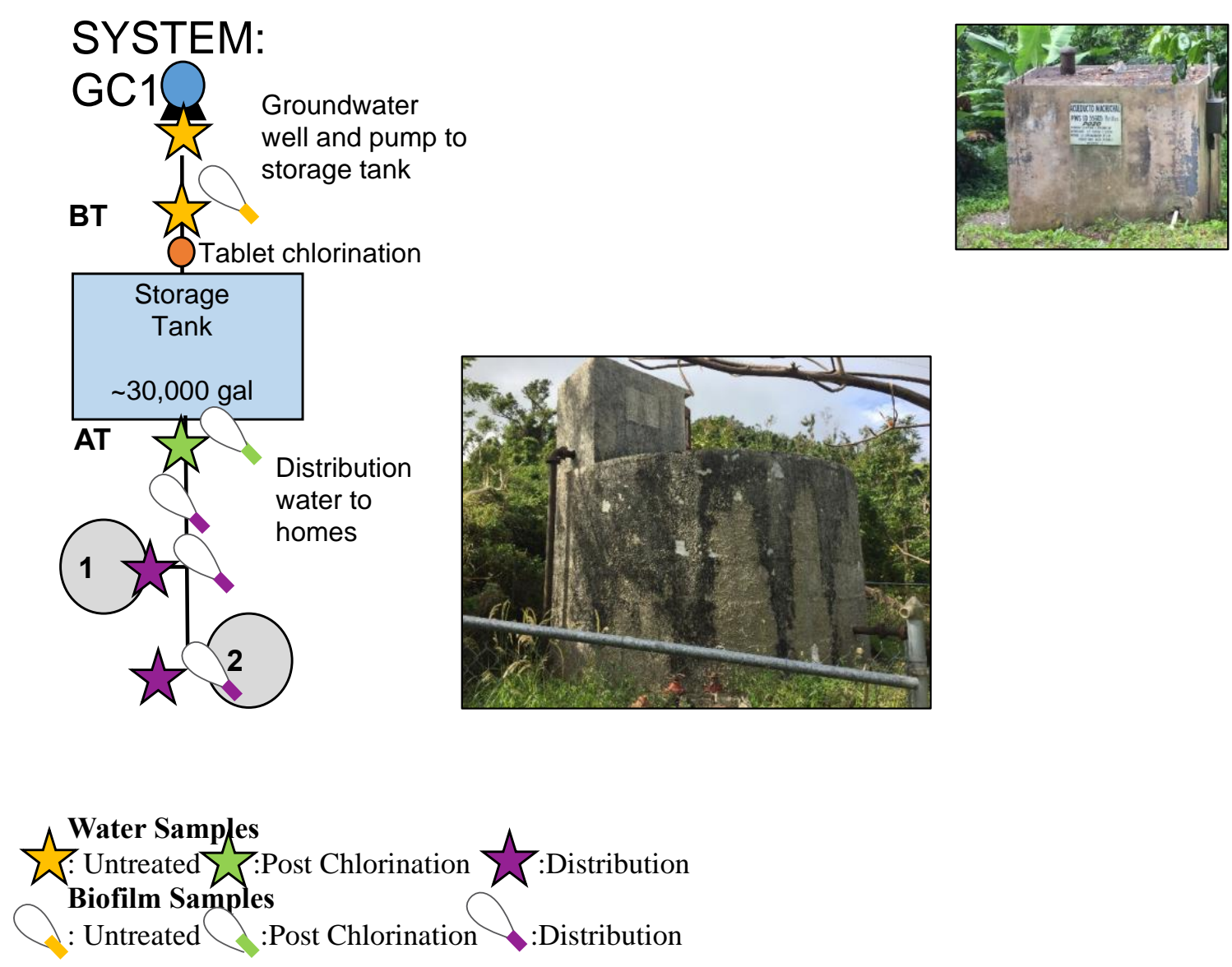

Figure S5: System GC1: process diagrams, sampling locations, and descriptions 


\section{SYSTEM: GC2}
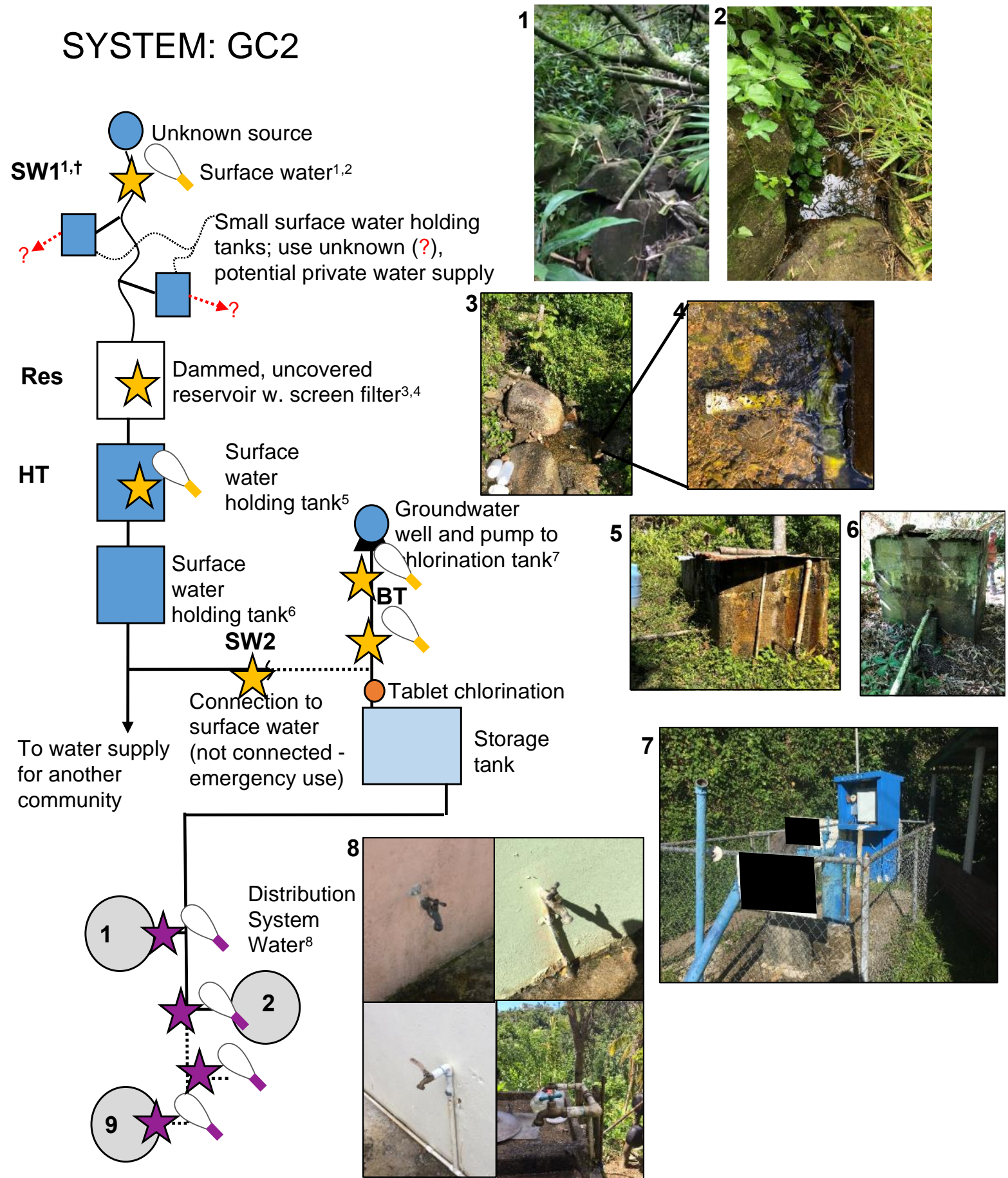

$\dagger$ : A point source for the groundwater could not be identified; the first (i.e., highest elevation) indication of water pooling was sampled

Sample names are in bold. SW: surface water; Res: reservoir; HT: holding tank; GW: groundwater n (1-9): house number sampled

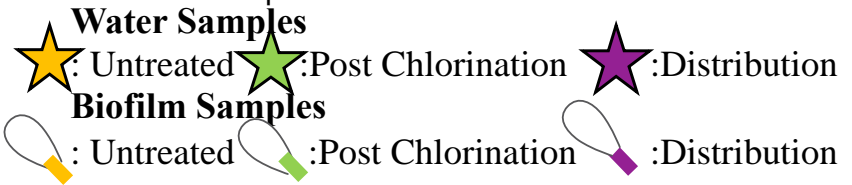

Figure S6: System GC2: process diagrams, sampling locations, and descriptions 


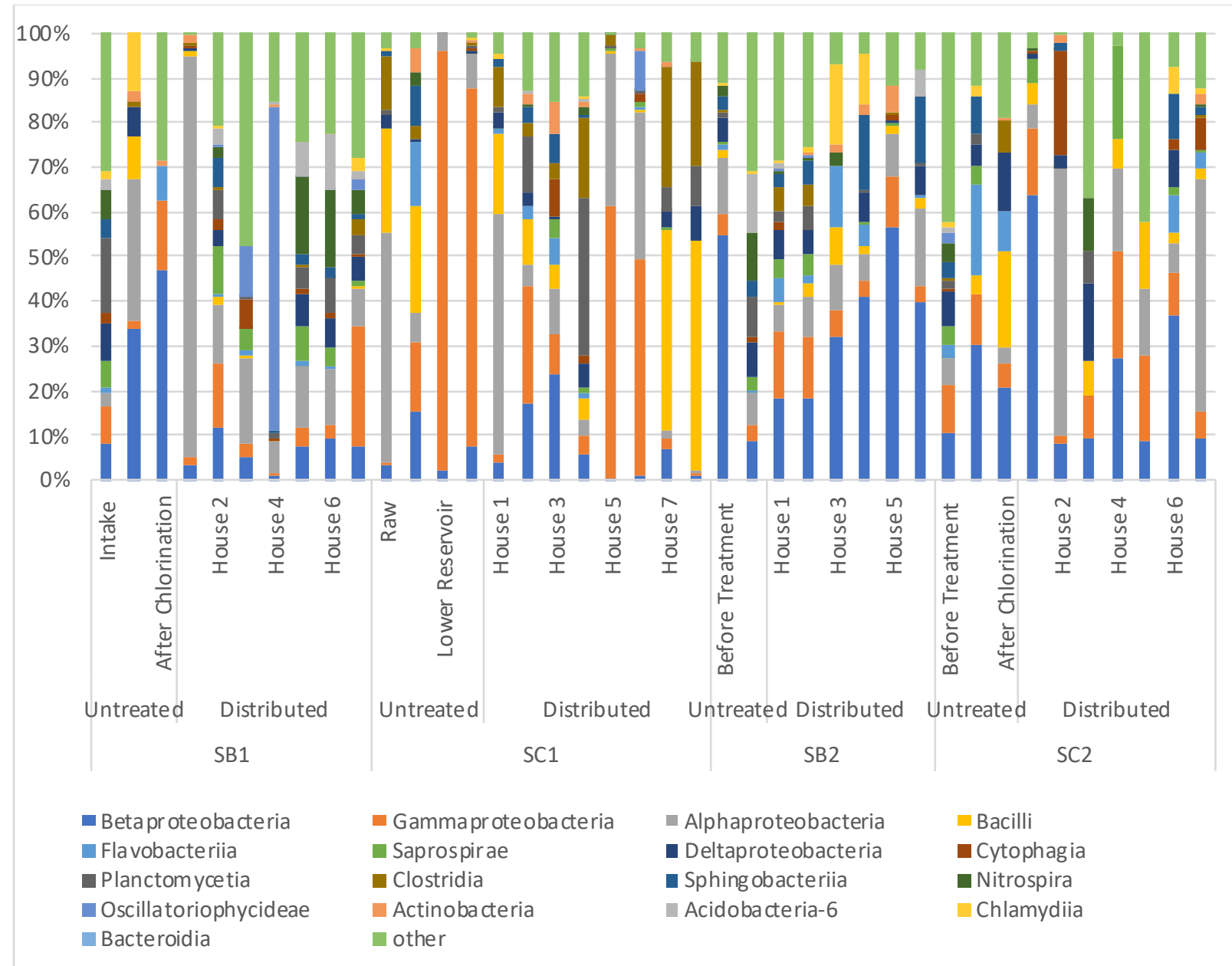

Figure S7: Water samples in small surface water samples with class associated taxonomy for $16 \mathrm{~S}$ amplicon sequencing. All classes with $>5 \%$ abundance are displayed. 


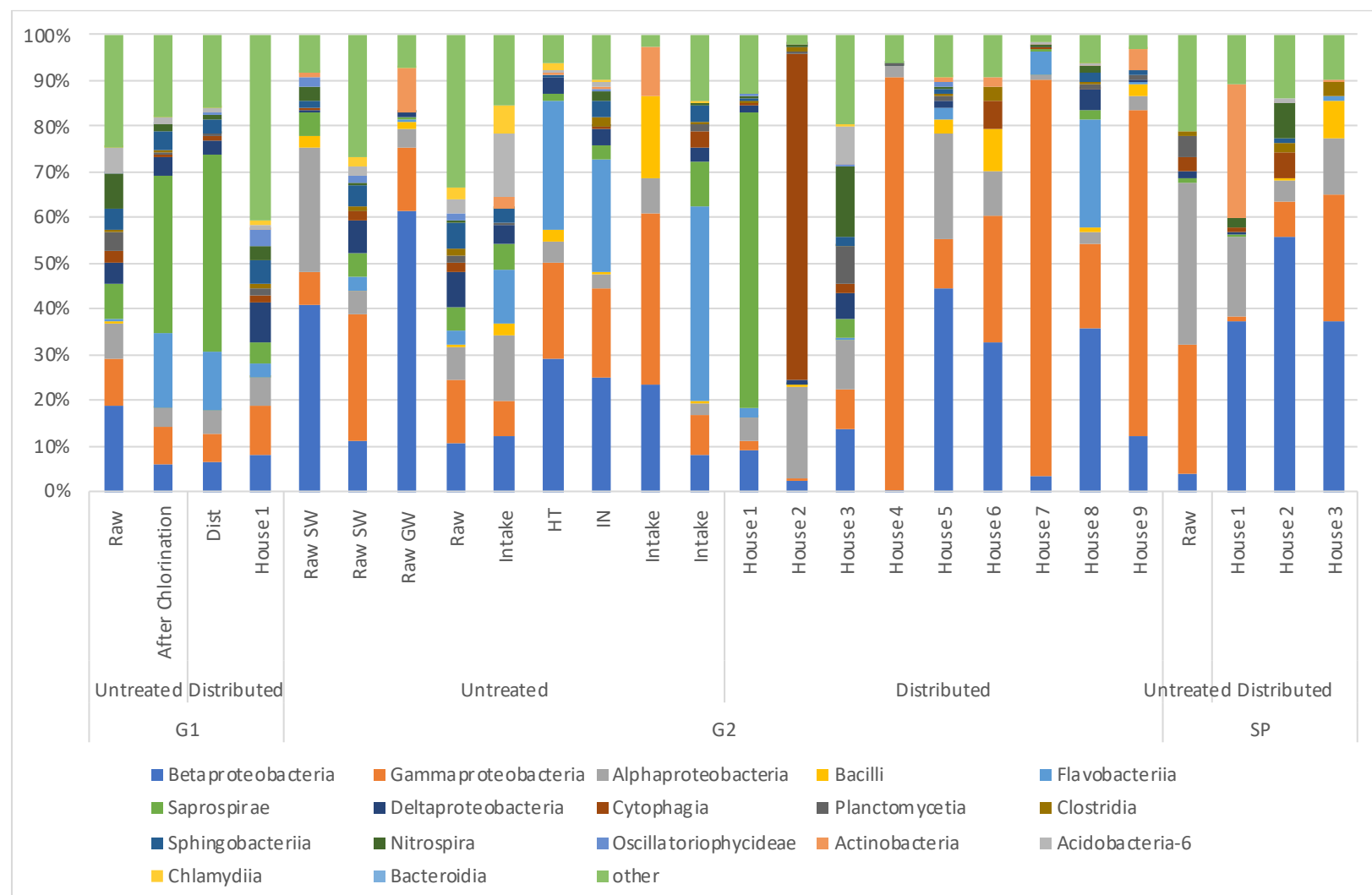

Figure S8: Water samples in small ground water and conventional treatment plant samples with class associated taxonomy for $16 \mathrm{~S}$ amplicon sequencing. All classes with $>5 \%$ abundance are displayed. 


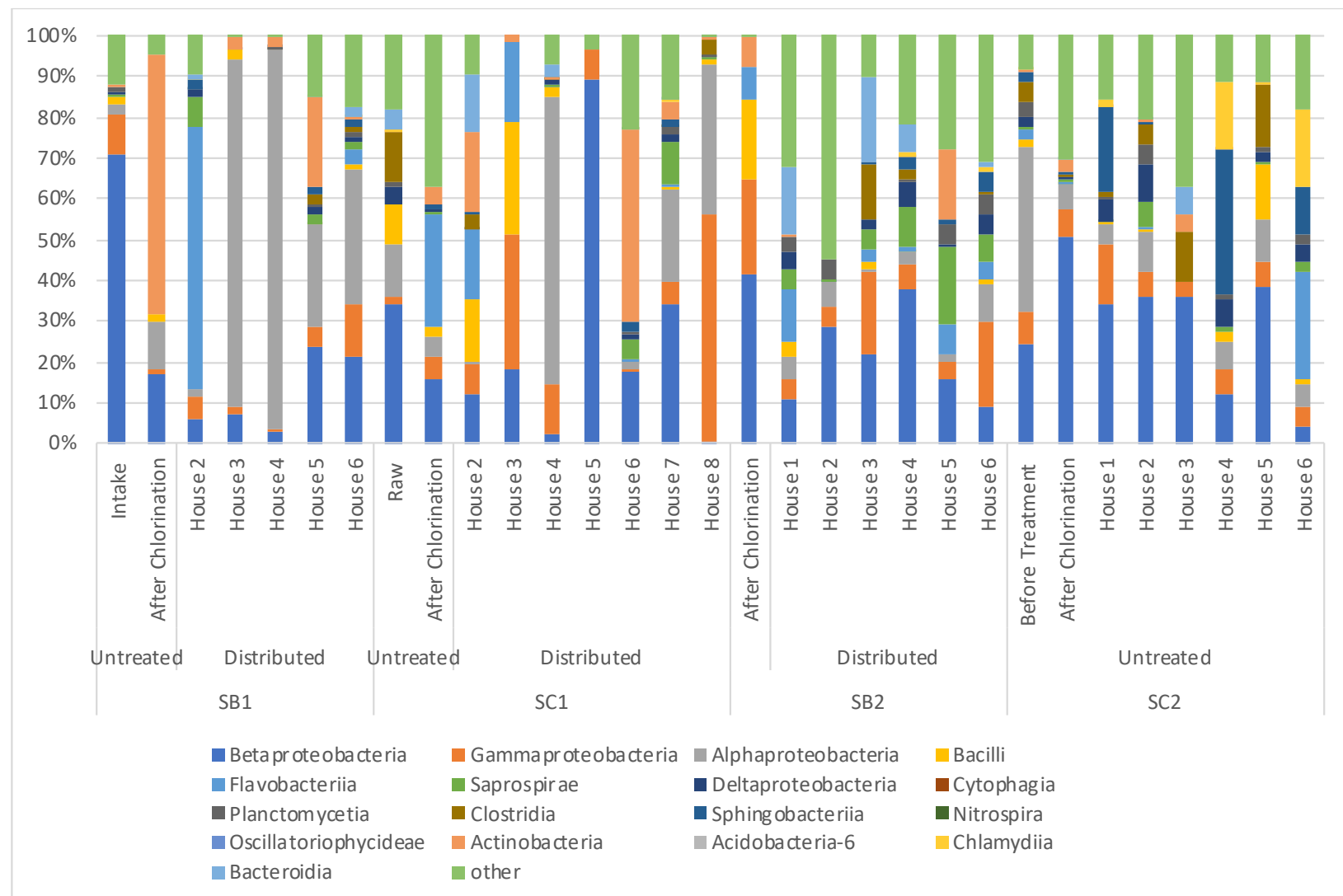

Figure S9: Biofilm samples with class associated taxonomy for $16 \mathrm{~S}$ amplicon sequencing. All classes with $>5 \%$ abundance are displayed. 


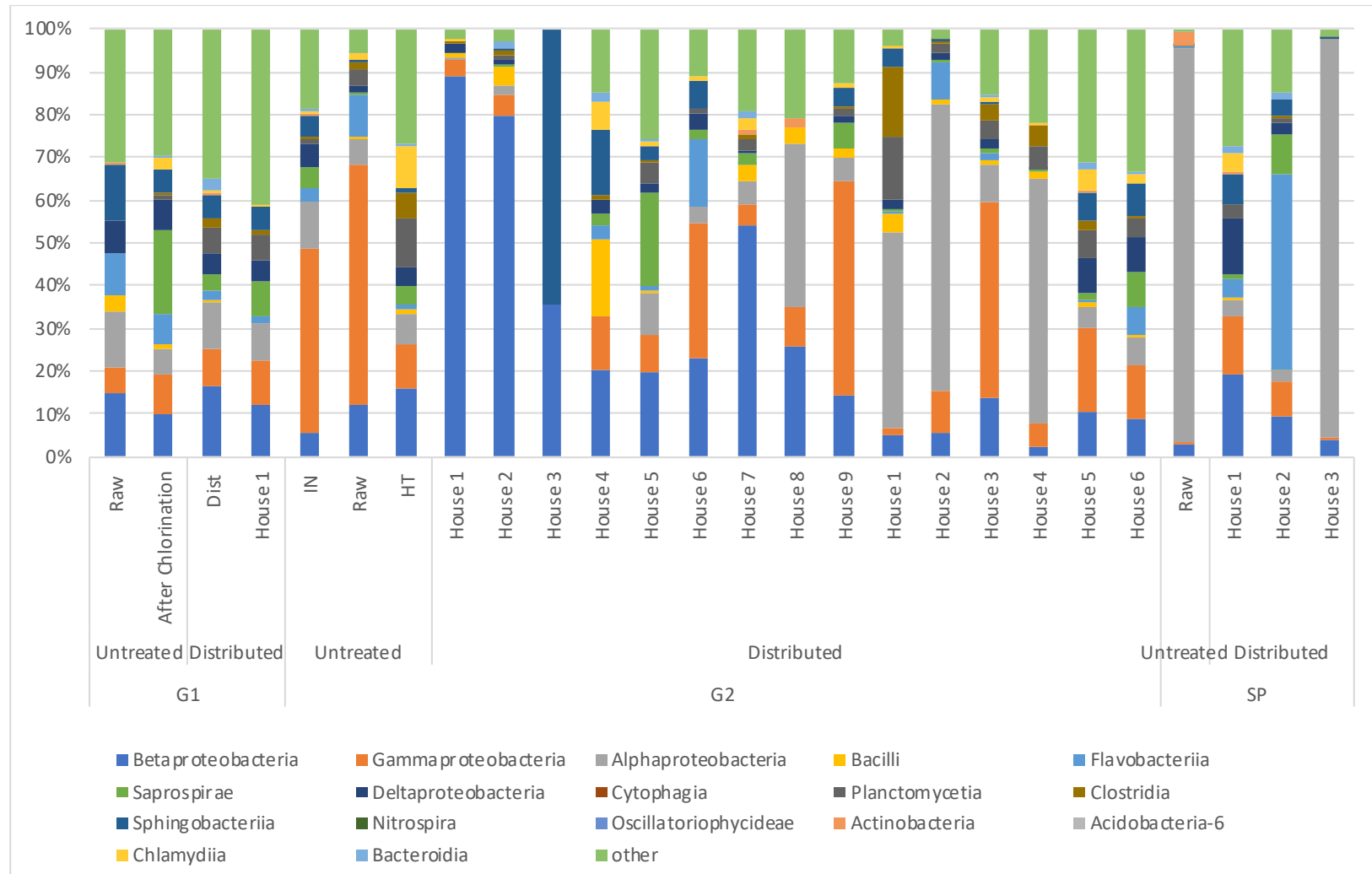

Figure S10: Biofilm samples with class associated taxonomy for $16 \mathrm{~S}$ amplicon sequencing. All classes with $>5 \%$ abundance are displayed. 


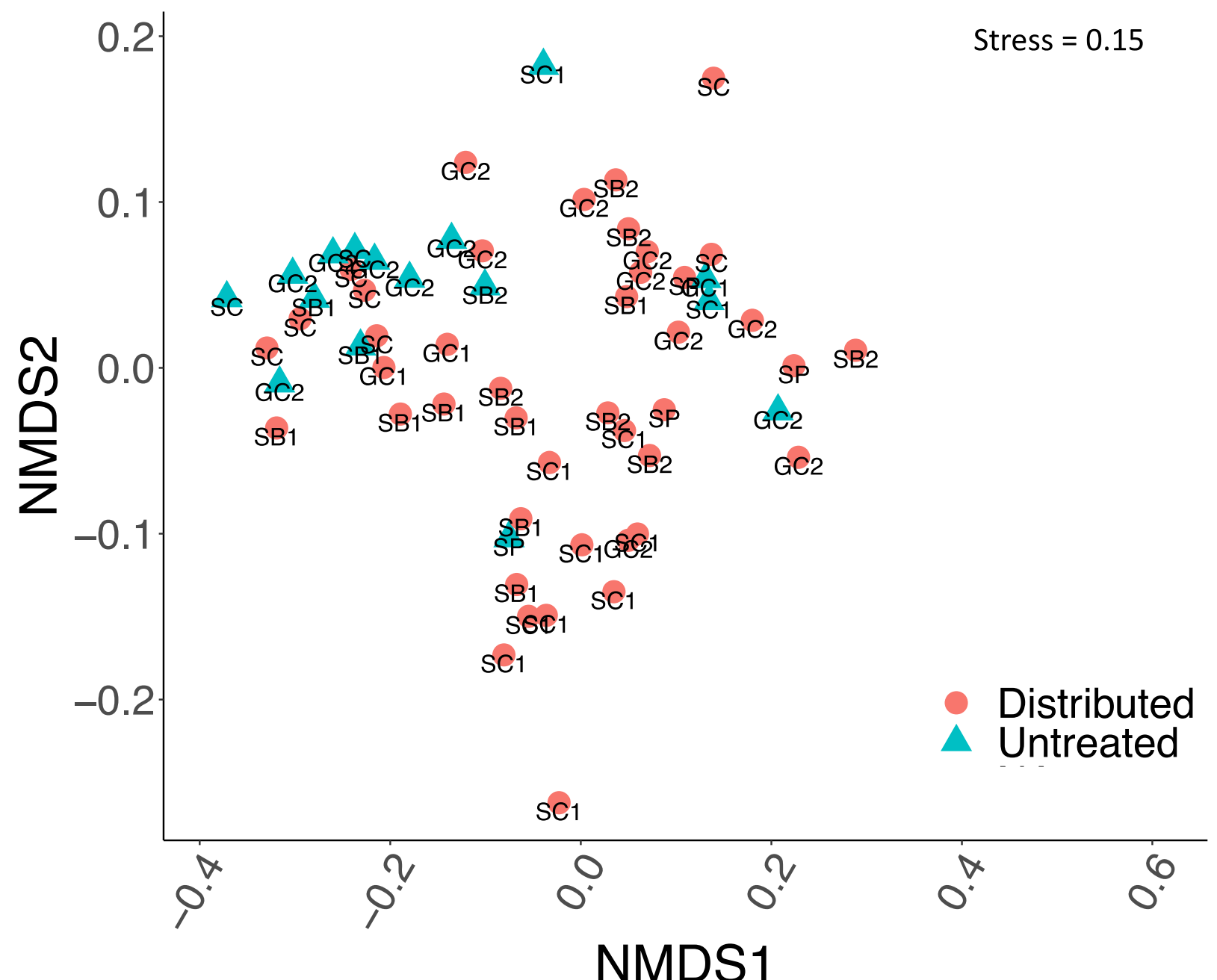

Figure S11: NMDS plot comparing distributed and untreated source water collection points for each system. Overall bacterial community composition was significantly different among the seven systems as a function of treatment (i.e., distributed versus untreated) $(R=0.042, p=0.001$, PERMANOVA) and source water type (i.e., groundwater versus surface water) $(\mathrm{R}=0.17, \mathrm{p}=$ 0.001, PERMANOVA).

Table S1: Naming Convention Corollary in Longitudinal Study

\begin{tabular}{|l|l|}
\hline Present Study Name & $\begin{array}{l}\text { Longitudinal Study } \\
\text { Name }\end{array}$ \\
\hline SB1 & A \\
\hline SC2 & B \\
\hline SB2 & D1 \\
\hline SC2 & D2 \\
\hline GC1 & E \\
\hline GC2 & F \\
\hline
\end{tabular}


Table S2: Available culture and microscopy data prior to Hurricane Maria

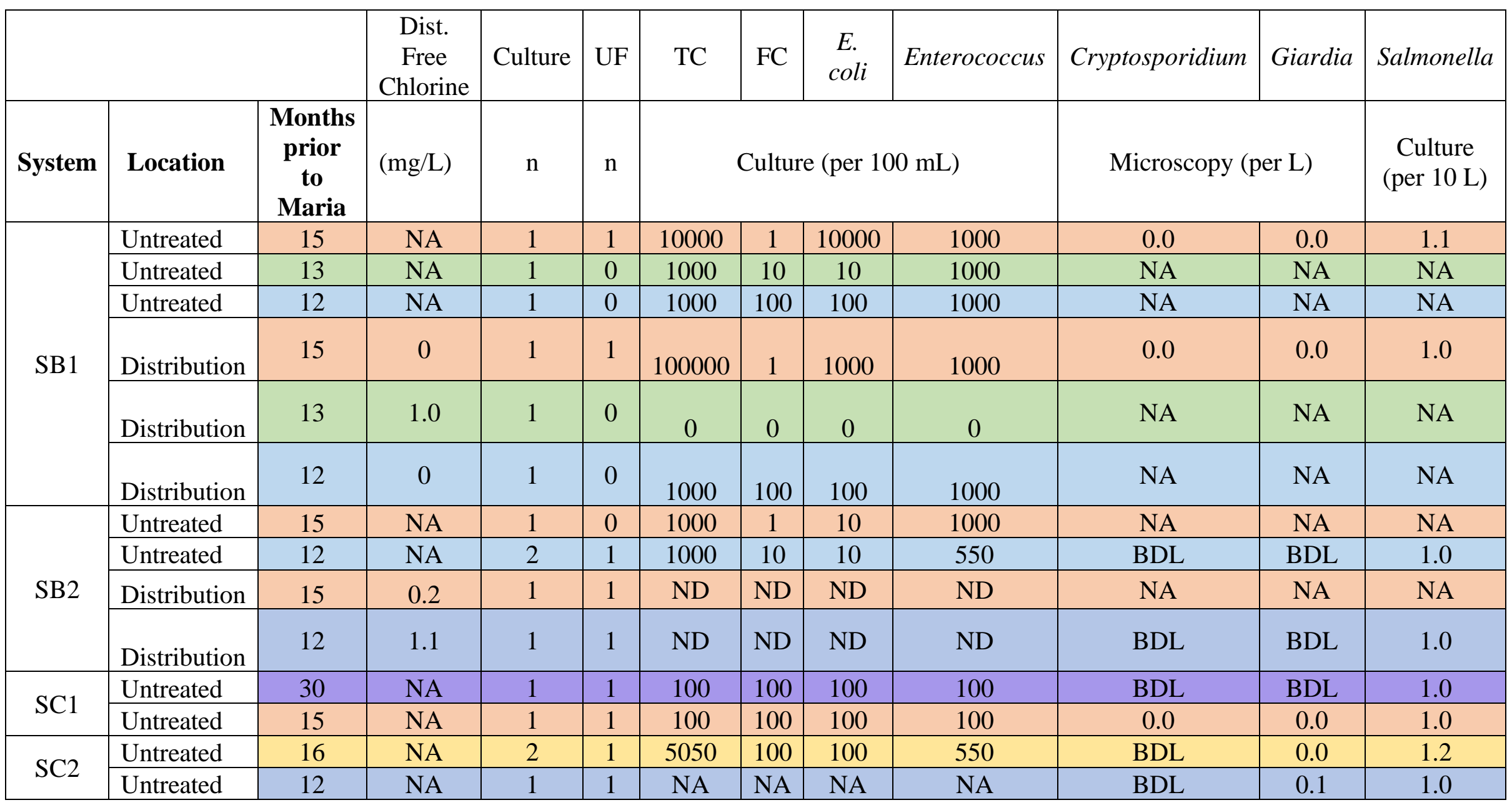

NA indicates that the analysis was not conducted at that time point; ND measurements were below the detection limit: $1 \mathrm{CFU} / 100 \mathrm{ML}$ for TC, FC, E.coli, and Enterococcus 
Table S3: Target Pathogens and Assays

\begin{tabular}{|c|c|c|}
\hline Target Pathogen & Analytical Rationale & Method of Detection / Primer Set (5'-3') \\
\hline $\begin{array}{l}\text { Cryptosporidium } \\
\text { spp. }\end{array}$ & $\begin{array}{l}\text { Eukaryotic water-borne parasite } \\
\text { that causes severe } \\
\text { gastrointestinal illness, resists } \\
\text { disinfection in oocyst form }\end{array}$ & $\begin{array}{l}\text { Culture }^{1}, 18 \text { S rRNA F } \\
\text { AGGGCTCCGGCATAACTTTCC }, ~ R \\
\text { GTATCTGTGACCCGTCCGAG }^{2}\end{array}$ \\
\hline Giardia lamblia & $\begin{array}{l}\text { Eukaryotic flagellated protozoan } \\
\text { that causes giardiasis. Found in } \\
\text { contaminated surface waters and } \\
\text { soils }\end{array}$ & $\begin{array}{l}\text { Culture }^{1} \text {, heat shock protein } \mathrm{F} \\
\text { AGGGCTCCGGCATAACT TTCC, R } \\
\text { GTATCTGTGACCCGTCCGAG }^{3}\end{array}$ \\
\hline Leptospira spp. & $\begin{array}{l}\text { Outbreak occurred in post-Maria } \\
\text { waters and sampled } \\
\text { communities. Bacterial water- } \\
\text { borne pathogen associated with } \\
\text { animal (e.g. rodent) urine. }\end{array}$ & $\begin{array}{l}\text { PCR hap } 1 \text { gene F GCAAGCATTACCGCTTGTGG, } \\
\text { R TGTTGGGGAAATCATACGAAC }^{4}\end{array}$ \\
\hline $\begin{array}{l}\text { Legionella spp. } \\
\text { (pneumophila) }\end{array}$ & $\begin{array}{l}\text { Leading cause of tap-water } \\
\text { associated disease and in the } \\
\text { U.S. }\end{array}$ & $\begin{array}{l}\text { qPCR F CCCATGAAGCCCGTTGAA, R } \\
\text { ACAATCAGCCAATTAGTACGAGTAGC, } \\
\text { HEX- } \\
\text { TCCACACCTCGCCTATCAACGTCGTAGT/3BH } \\
\text { Q-1 (mip qPCR F } \\
\text { AAAGGCATGCAAGACGCTATG, R } \\
\text { GAAACTTGTTAAGAACGTCTTTCATTTG, } \\
\text { FAM-TGGCGCTCAATTGGCTTTAACCGA) } \\
\text { FA }\end{array}$ \\
\hline $\begin{array}{l}\text { Mycobacterium } \\
\text { spp.(avium) }\end{array}$ & $\begin{array}{l}\text { Most commonly associated with } \\
\text { NTM lung disease }\end{array}$ & 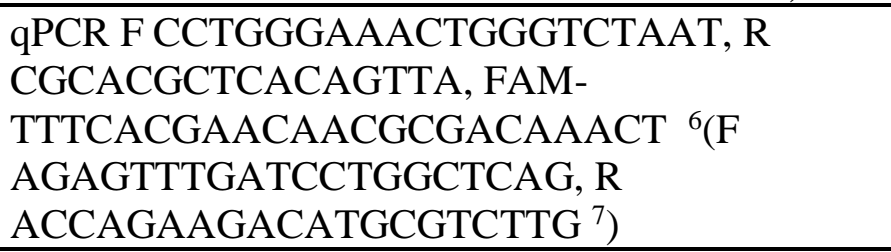 \\
\hline Salmonella spp. & $\begin{array}{l}\text { Enteric and environmental } \\
\text { bacteria found in fecal } \\
\text { contaminated waters and soils }\end{array}$ & $\begin{array}{l}\text { PCR invA gene } \mathrm{F} \\
\text { GTGAAATTATCGCCACGTTCGGGCAA R } \\
\text { TCATCGCACCGTCAAAGGAACC }^{8}, \text { Culture }^{9}\end{array}$ \\
\hline $\begin{array}{l}\text { Shiga toxin } \\
\text { producing } E \text {. coli }\end{array}$ & $\begin{array}{l}\text { Enteric and environmental } \\
\text { bacteria found in fecal } \\
\text { contaminated waters and soils }\end{array}$ & $\begin{array}{l}\text { PCR } s t x_{l} \text { F ACACTGGATGATCTCAGTGG R } \\
\text { CTGAATCCCCTCCATTATG, stx } x_{2} \text { F } \\
\text { CCATGACAACGGACAGCAGTT R } \\
\text { CCTGTCAACTGAGCAGCACTTTG }{ }^{10} \\
\end{array}$ \\
\hline 16S rRNA gene & $\begin{array}{l}\text { Highly conserved bacterial } \\
\text { housekeeping gene used for } \\
\text { taxonomy and as proxy for total } \\
\text { bacterial cell count }\end{array}$ & $\begin{array}{l}\text { qPCR F CGGTGAATACGTTCYCGG,R } \\
\text { GGWTACCTTGTTACGACTT,11, 16S rRNA } \\
\text { Amplicon Sequencing F: } \\
\text { GTGCCAGCMGCCGCGGTAA12 R: } \\
\text { CGYCAATTYMTTTRAGTTT13 }\end{array}$ \\
\hline
\end{tabular}


Table S4: QPCR run and calibration parameters by assay

\begin{tabular}{|c|c|c|c|c|c|}
\hline $\begin{array}{l}\text { Target } \\
\text { pathogen/gene }\end{array}$ & Reference & $\begin{array}{l}\text { Annealing } \\
\text { Temperatu } \\
\text { re }\left({ }^{\circ} \mathbf{C}\right)\end{array}$ & $\begin{array}{l}\text { R2 } \\
\text { (Ave. } \pm \\
\text { Std. } \\
\text { Dev.) }\end{array}$ & $\begin{array}{l}\text { Efficiency } \\
\text { (Ave. } \pm \\
\text { Std. Dev.) }\end{array}$ & $\begin{array}{l}\text { Limit of } \\
\text { Quantification } \\
\text { gc/ } \mathrm{mL}\end{array}$ \\
\hline $\begin{array}{l}\text { General } \\
\text { bacterial count } \\
\text { (16S rRNA } \\
\text { gene) }\end{array}$ & $\begin{array}{l}\text { Suzuki et al., } \\
\text { 2000, Applied } \\
\text { and } \\
\text { Environmental } \\
\text { Microbiology }{ }^{11}\end{array}$ & 60 & $\begin{array}{l}0.99 \pm \\
0.01\end{array}$ & $\begin{array}{l}95.4 \pm \\
7.61\end{array}$ & 0.1 \\
\hline $\begin{array}{l}\text { Legionella spp. } \\
\text { (23S rRNA) }\end{array}$ & $\begin{array}{l}\text { Nazarian et al., } \\
\text { 2008, Diagn. } \\
\text { Microbiol. Infect. } \\
\text { Dis. } 5\end{array}$ & 58.5 & $\begin{array}{l}0.98 \pm \\
0.01\end{array}$ & $\begin{array}{l}91.2 \pm \\
14.9\end{array}$ & 1 \\
\hline $\begin{array}{l}\text { L. pneumophila } \\
\text { (mip) }\end{array}$ & $\begin{array}{l}\text { Nazarian et al., } \\
\text { 2008, Diagn. } \\
\text { Microbiol. Infect. } \\
\text { Dis. } 5\end{array}$ & 60 & $\begin{array}{l}0.98 \pm \\
0.00\end{array}$ & $94.2 \pm 9.3$ & 0.1 \\
\hline $\begin{array}{l}\text { Mycobacterium } \\
\text { spp. (16S rRNA } \\
\text { gene) }\end{array}$ & $\begin{array}{l}\text { Radomski et al., } \\
\text { 2010, Appl. } \\
\text { Environ. } \\
\text { Microbiol. }{ }^{6}\end{array}$ & 55 & $\begin{array}{l}0.99 \pm \\
0.01\end{array}$ & $89.8 \pm 5.7$ & 1 \\
\hline $\begin{array}{l}\text { Mycobacterium } \\
\text { avium (16S } \\
\text { rRNA gene) }\end{array}$ & $\begin{array}{l}\text { Wilton, 1992, } \\
\text { Genome Res. }^{7}\end{array}$ & 68 & $\begin{array}{l}0.99 \pm \\
0.01\end{array}$ & $83.7 \pm 6.3$ & 1 \\
\hline
\end{tabular}

Table S5: qPCR dilutions by sample

See Excel

Table S6: Water chemistry and Inorganics concentrations

See Excel

Table S7: Additional pathogens/taxa screened by 16S amplicon sequencing

\begin{tabular}{|l|l|}
\hline $\begin{array}{l}\text { Family: Enterobacteriaceae } \\
\text { Genera: Salmonella, Escherichia coli, Klebsiella, } \\
\text { and Shigella. }\end{array}$ & $\begin{array}{l}\text { WHO global priority pathogen family that contains } \\
\text { several genera that can be pathogenic }\end{array}$ \\
\hline Genus: Acinetobacter & WHO global priority pathogen containing genus \\
\hline Genus: Pseudomonas & WHO global priority pathogen containing genus \\
\hline Genus:Staphylococcus & WHO global priority pathogen containing genus \\
\hline $\begin{array}{l}\text { Family: Helicobacteraceae; } \\
\text { Genus: Helicobacter }\end{array}$ & $\begin{array}{l}\text { Family that contains WHO global priority } \\
\text { pathogens. Because the genus of interest was not } \\
\text { detected, counts were conducted for unclassified } \\
\text { genera at the family level instead. }\end{array}$ \\
\hline $\begin{array}{l}\text { Family: Campylobacteraceae; } \\
\text { Genus: Campylobacter, Arcobacter }\end{array}$ & $\begin{array}{l}\text { Family that contains WHO global priority } \\
\text { pathogens. Because the genus of interest was not }\end{array}$ \\
\hline
\end{tabular}




\begin{tabular}{|l|l|}
\hline & $\begin{array}{l}\text { detected, counts were conducted for unclassified } \\
\text { genera at the family level instead. }\end{array}$ \\
\hline Genus: Streptococcus & WHO global priority pathogen containing genus \\
\hline Genus: Haemophilus & WHO global priority pathogen containing genus \\
\hline
\end{tabular}

Table S8: Pathogen Detections with 16S rRNA Amplicon 


\begin{tabular}{|c|c|c|c|c|c|c|c|c|c|c|c|c|c|c|}
\hline \multirow[b]{2}{*}{ System } & \multirow[b]{2}{*}{ Location } & \multicolumn{13}{|c|}{ Water } \\
\hline & & $\mathbf{n}$ & 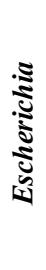 & 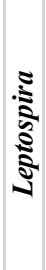 & 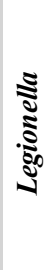 & 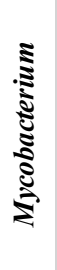 & 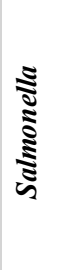 & 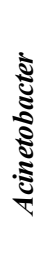 & 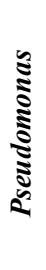 & 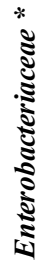 & 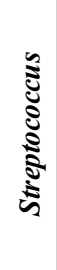 & 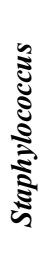 & $\frac{\sqrt{3}}{\sqrt[3]{3}}$ & 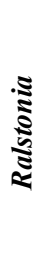 \\
\hline \multirow{3}{*}{ SB1 } & Untreated & 2 & 0 & 0 & 0 & 0 & 0 & 1 & 1 & 2 & 0 & 0 & 0 & 1 \\
\hline & After Chlorination & 1 & 0 & 0 & 1 & 1 & 0 & 1 & 1 & 1 & 1 & 2 & 0 & 1 \\
\hline & \begin{tabular}{|l|} 
Distribution \\
\end{tabular} & 7 & 0 & 0 & 4 & 2 & 0 & 6 & 5 & 6 & 6 & 2 & 5 & 6 \\
\hline \multirow{3}{*}{ SB2 } & Untreated & 1 & 0 & 0 & 0 & 0 & 0 & 0 & 1 & 0 & 0 & 0 & 0 & 1 \\
\hline & After Chlorination & 1 & 0 & 0 & 0 & 1 & 0 & 0 & 1 & 1 & 1 & 0 & 1 & 1 \\
\hline & \begin{tabular}{|l|} 
Distribution \\
\end{tabular} & 6 & 0 & 0 & 0 & 2 & 0 & 2 & 5 & 6 & 2 & 1 & 5 & 7 \\
\hline \multirow{3}{*}{ SC1 } & Untreated & 2 & 0 & 0 & 0 & 0 & 0 & 2 & 2 & 2 & 2 & 1 & 1 & 1 \\
\hline & After Chlorination & 1 & 0 & 0 & 0 & 0 & 0 & 1 & 1 & 1 & 0 & 0 & 1 & 1 \\
\hline & \begin{tabular}{|l|} 
Distribution \\
\end{tabular} & 10 & 0 & 0 & 0 & 5 & 0 & 7 & 6 & 5 & 6 & 3 & 6 & 7 \\
\hline \multirow{3}{*}{$\mathrm{SC} 2$} & Untreated & 2 & 0 & 1 & 0 & 0 & 0 & 1 & 1 & 2 & 0 & 0 & 0 & 1 \\
\hline & After Chlorination & 1 & 0 & 1 & 0 & 0 & 0 & 1 & 1 & 1 & 0 & 0 & 0 & 0 \\
\hline & \begin{tabular}{|l|} 
Distribution \\
\end{tabular} & 7 & 0 & 1 & 1 & 0 & 0 & 3 & 2 & 4 & 1 & 1 & 1 & 2 \\
\hline \multirow{3}{*}{$\mathrm{GC} 1$} & Untreated & 2 & 0 & 0 & 0 & 0 & 0 & 0 & 0 & 1 & 1 & 0 & 0 & 0 \\
\hline & After Chlorination & 1 & 0 & 0 & 0 & 0 & 0 & 0 & 0 & 0 & 0 & 0 & 0 & 0 \\
\hline & Distribution & 2 & 0 & 0 & 0 & 0 & 0 & 2 & 2 & 2 & 2 & 2 & 0 & 0 \\
\hline \multirow{3}{*}{$\mathrm{GC} 2$} & $\begin{array}{l}\text { Previous } \\
\text { Untreated** }\end{array}$ & 4 & 0 & 1 & 0 & 0 & 0 & 0 & 0 & 1 & 0 & 1 & 1 & 1 \\
\hline & Untreated & 2 & 0 & 2 & 5 & 2 & 0 & 5 & 4 & 5 & 1 & 1 & 3 & 3 \\
\hline & Distribution & 9 & 0 & 0 & 1 & 3 & 0 & 8 & 7 & 6 & 4 & 2 & 4 & 5 \\
\hline \multirow{2}{*}{ SP } & Untreated & 1 & 0 & 1 & 0 & 0 & 0 & 0 & 0 & 0 & 0 & 0 & 0 & 0 \\
\hline & Distribution & 3 & 0 & 0 & 0 & 0 & 0 & 2 & 0 & 3 & 2 & 1 & 1 & 2 \\
\hline & & \multicolumn{13}{|c|}{ Biofilm } \\
\hline \multirow{3}{*}{ SB1 } & Untreated & 1 & 0 & 0 & 0 & 0 & 0 & 0 & 1 & 1 & 0 & 0 & 0 & 0 \\
\hline & After Chlorination & 1 & 0 & 0 & 0 & 0 & 0 & 0 & 0 & 1 & 1 & 0 & 0 & 0 \\
\hline & \begin{tabular}{|l|} 
Distribution \\
\end{tabular} & 5 & 0 & 1 & 1 & 3 & 0 & 5 & 4 & 4 & 2 & 3 & 5 & 5 \\
\hline \multirow{2}{*}{ SB2 } & After Chlorination & 1 & 0 & 0 & 0 & 0 & 0 & 0 & 0 & 1 & 0 & 0 & 1 & 1 \\
\hline & \begin{tabular}{|l|} 
Distribution \\
\end{tabular} & 6 & 0 & 0 & 0 & 0 & 0 & 4 & 2 & 4 & 2 & 4 & 3 & 3 \\
\hline \multirow{3}{*}{$\mathrm{SC} 1$} & Untreated & 1 & 0 & 0 & 0 & 1 & 0 & 1 & 1 & 1 & 0 & 1 & 1 & 1 \\
\hline & After Chlorination & 1 & 0 & 0 & 0 & 0 & 0 & 1 & 1 & 1 & 0 & 0 & 0 & 0 \\
\hline & \begin{tabular}{|l|} 
Distribution \\
\end{tabular} & 7 & 0 & 0 & 1 & 4 & 0 & 7 & 4 & 3 & 3 & 5 & 6 & 5 \\
\hline \multirow{3}{*}{$\mathrm{SC} 2$} & Untreated & 1 & 0 & 0 & 0 & 0 & 0 & 0 & 1 & 0 & 0 & 1 & 1 & 1 \\
\hline & After Chlorination & 1 & 0 & 0 & 0 & 1 & 0 & 0 & 1 & 0 & 0 & 1 & 1 & 1 \\
\hline & Distribution & 6 & 0 & 1 & 1 & 1 & 0 & 1 & 3 & 2 & 2 & 3 & 3 & 4 \\
\hline \multirow{3}{*}{$\mathrm{GC} 1$} & Untreated & 1 & 0 & 0 & 1 & 0 & 0 & 1 & 1 & 1 & 1 & 1 & 1 & 1 \\
\hline & After Chlorination & 1 & 0 & 0 & 1 & 0 & 0 & 1 & 1 & 1 & 0 & 1 & 0 & 1 \\
\hline & Distribution & 2 & 0 & 0 & 2 & 0 & 0 & 1 & 1 & 2 & 1 & 1 & 1 & 2 \\
\hline \multirow{3}{*}{$\mathrm{GC} 2$} & $\begin{array}{c}\text { Previous } \\
\text { Untreated } * *\end{array}$ & 2 & 0 & 0 & 0 & 0 & 0 & 1 & 1 & 1 & 0 & 0 & 0 & 0 \\
\hline & Untreated & 2 & 0 & 1 & 0 & 1 & 0 & 2 & 2 & 2 & 1 & 2 & 2 & 2 \\
\hline & Distribution & 9 & 0 & 1 & 0 & 9 & 0 & 9 & 9 & 8 & 4 & 5 & 9 & 9 \\
\hline \multirow{2}{*}{ SP } & Untreated & 1 & 0 & 1 & 0 & 0 & 0 & 1 & 0 & 1 & 1 & 1 & 1 & 1 \\
\hline & Distribution & 3 & 0 & 0 & 0 & 0 & 0 & 1 & 0 & 2 & 2 & 2 & 1 & 2 \\
\hline
\end{tabular}

* family level **Previous untreated in System GC2 refers to the surface water source that was used immediately after Hurricane Maria before the generator was installed 


\section{References:}

1. U.S. EPA, Method 1623: Cryptosporidium and Giardia in Water by Filtration/IMS/FA. 815-R-05-002 2005.

2. Johnson, D. W.; Pieniazek, N. J.; Griffin, D. W.; Misener, L.; Rose, J. B., Development of a PCR protocol for sensitive detection of Cryptosporidium oocysts in water samples. Appl Environ Microb 1995, 61, (11), 3849-3855.

3. Rochelle, P. A.; Ferguson, D. M.; Handojo, T. J.; De Leon, R.; Stewart, M. H.; Wolfe, R. L., An assay combining cell culture with reverse transcriptase PCR to detect and determine the infectivity of waterborne Cryptosporidium parvum. Appl Environ Microb 1997, 63, (5), 20292037.

4. $\quad$ Branger, C.; Blanchard, B.; Fillonneau, C.; Suard, I.; Aviat, F.; Chevallier, B.; AndréFontaine, G., Polymerase chain reaction assay specific for pathogenic Leptospira based on the gene hap1 encoding the hemolysis-associated protein-1. FEMS microbiology letters 2005, 243, (2), 437-445.

5. Nazarian, E. J.; Bopp, D. J.; Saylors, A.; Limberger, R. J.; Musser, K. A., Design and implementation of a protocol for the detection of Legionella in clinical and environmental samples. Diagnostic Microbiology and Infectious Disease 2008, 62, (2), 125-132.

6. $\quad$ Radomski, N.; Lucas, F. S.; Moilleron, R.; Cambau, E.; Haenn, S.; Moulin, L., Development of a real-time qPCR method for detection and enumeration of Mycobacterium spp. in surface water. Appl. Environ. Microbiol. 2010, 76, (21), 7348-7351.

7. Wilton, S.; Cousins, D., Detection and identification of multiple mycobacterial pathogens by DNA amplification in a single tube. Genome Research 1992, 1, (4), 269-273.

8. Rahn, K.; De Grandis, S. A.; Clarke, R. C.; McEwen, S. A.; Galan, J. E.; Ginocchio, C.; Curtiss Iii, R.; Gyles, C. L., Amplification of an invA gene sequence of Salmonella typhimurium by polymerase chain reaction as a specific method of detection of Salmonella. Molecular and cellular probes 1992, 6, (4), 271-279.

9. Water Environmental Federation, Standard methods for the examination of water and wastewater. American Public Health Association (APHA): Washington, DC, USA 2005.

10. Fagan, P. K.; Hornitzky, M. A.; Bettelheim, K. A.; Djordjevic, S. P., Detection of Shigalike toxin (stx1 andstx2), intimin (eaeA), and enterohemorrhagic Escherichia coli (EHEC) hemolysin (EHEC hlyA) genes in animal feces by multiplex PCR. Appl Environ Microb 1999, 65, (2), 868-872.

11. Suzuki, M. T.; Taylor, L. T.; DeLong, E. F., Quantitative analysis of small-subunit rRNA genes in mixed microbial populations via 5'-nuclease assays. Appl Environ Microb 2000, 66, (11), 4605-4614.

12. Caporaso, J. G.; Kuczynski, J.; Stombaugh, J.; Bittinger, K.; Bushman, F. D.; Costello, E. K.; Fierer, N.; Pena, A. G.; Goodrich, J. K.; Gordon, J. I., QIIME allows analysis of highthroughput community sequencing data. Nature methods 2010, 7, (5), 335.

13. Quince, C.; Lanzen, A.; Davenport, R. J.; Turnbaugh, P. J., Removing noise from pyrosequenced amplicons. BMC Bioinformatics 2011, 12, (1), 38. 